\title{
A Chinese Tai Chi Model: An Integrative Model beyond the Dichotomy of Student-Centered Learning and Teacher-Centered Learning
}

\author{
Fan Yang ${ }^{1} \&$ Jing Lin $^{2}$ \\ ${ }^{1}$ Office of Undergraduate Education, University of Science and Technology of China, Hefei, China \\ ${ }^{2}$ College of Education, University of Maryland, College Park, USA \\ Correspondence: Jing Lin, Counseling, Higher Education and Special Education, College of Education, \\ University of Maryland, Maryland, USA. Tel: 1-301-405-3568.
}

Received: August 24, 2016

doi:10.20849/aes.v1i2.61
Accepted: September 7, 2016

Online Published: September 13, 2016

URL: http://dx.doi.org/10.20849/aes.v1i2.61

\begin{abstract}
There are two types of educational approaches: one is student-centered learning and the other is teacher-centered learning. Each approach has its strengths and challenges. Hence debate arises as to which one is more appropriate and this makes some educators confused. In the background of globalization and internationalization of education, the influence of student-centered theory is very profound and far-reaching. Rethinking the student-centered or teacher centered education is important for the development of modern education. We argue that the ancient Chinese Tai Chi philosophy may be an alternative approach to mediate this controversy by helping people to understand the dynamic balance of teaching and learning. According to Tai Chi philosophy, student may be considered as yin, while teacher as yang. A Tai Chi model of education focuses on the dynamic interaction of the teacher and the student. Moreover, based on the vision of the Tai Chi philosophy, a number of classical western education theories may be brought to a new perspective. The combination of the traditional Chinese philosophies and related western educational theories might open another window for modern educational theories development. In short, through the perspective of Tai Chi, education is a combination of interactive factors and approaches rather than a dichotomy of teaching and learning, and it requires wisdom for dynamic complementary exploration rather than learning as static events in the class.
\end{abstract}

Keywords: Tai Chi, student-centered, teacher-centered, dynamic balance and integration

\section{Introduction}

The process of education is influenced by a number of factors, but the two main influences are the student and the teacher, hence there are two main educational approaches: one that puts student at the center of the learning process, the other that places teacher in the central role in the education process. These two approaches have been described as "student-centered" or "teacher-centered" learning.

In recent decades, teacher-centered learning is much-maligned, while student-centered learning, especially in pedagogical aspects, has been praised highly and promoted. However, just as the challenges facing traditional teacher-centered learning, the practice of student-centered learning is not without problems. Controversy over the two types of learning has never ceased. In the era of globalization and internationalization of education, the influence of student-centered learning theory is very deep and far-reaching. However, teacher-centered approach has been practiced with a long history, hence debate also arises and this makes some educators perplexed or frustrated. Rethinking the balance of student-centered or teacher-centered education is important to the development of modern education.

\section{Definition: Review and Renew}

Student-centered learning or teaching, also known as learner-centered education, can be traced back to the progressive education movement in the early part of the 20th century and in constructivist learning theories. Progressivism, Social Reconstructionism, and Existentialism place the learner at the center of the educational process (Sadker \& Zittleman, 2006). The student-centered approach is often considered as the core feature of "progressive education" or "Constructivist Learning." 


\subsection{Student-Centered Learning Model}

The narrow definition of the student-centered model is that students dominate how, what, and when learning occurs. In Chall's (2000) description, the student-centered model "tends to view learning as good in and of itself and as a source of pleasure. If learning is not controlled too much by teachers, schools, and parents, it will come naturally to the learner" (p. 6). In a student-centered classroom, the teacher's role is to serve mainly as a facilitator for student-directed learning. Under this philosophy it is regarded as a bad practice for teachers to actually do much teaching. They are suggested to act as "the guide on the side" rather than "the sage on the stage" (King, 1993; Cunningham, 2008).

What is worth mentioning is that there is a growing trend toward an over generalizing definition of the student-centered approach. It seems that every pedagogy which attaches importance to the positive roles of students has been labeled as student-centered, such as collaborative/cooperative learning, project-based/problem-based learning (PBL), reflective learning, authentic learning, and discovery leaning, etc.. There are teachers who lead and direct most parts of the class, but they prefer to describe their class as of a student-centered style because they think they have tried to meet students' needs and assist students in accordance with their individual aptitude. But in fact, some of the above learning styles have significant characteristics of a teacher-centered approach, and there is an overlap between a student-centered and a teacher-centered approach in real educational situations.

\subsection{Teacher-Centered Learning Model}

Teacher-centered learning is a traditional education model. In the west, it may have its origin in Socratic inquiry, developed from Plato's Socratic Dialogues. Socrates, the ancient Greek master, asked carefully crafted questions that would lead students to an understanding of their own. "While this method is very teacher centered, the student, with the instructor's guidance, does the exploring and discovering" (Halstead, 2011). Two philosophies, essentialism and perennialism, are claimed as teacher-centered philosophies (Masouleh \& Jooneghani, 2012). Scholars argue that a key function of school is to root young people in the essential knowledge for good citizenships, the learning of the basics. Perennialism focuses on the values associated with reason, and it is also the basic content of education. The teacher is the one to direct the class, promote high academic standards and discipline, and lead student practice and rehearsal of the basics. The content is not selected because of student interest but because it represents the essentials and perennials (Bull, 2014). In China, teacher-centered learning has long been the tradition, as teachers are endowed with the role of "passing on the Tao, teaching expert knowledge and answering students' questions."

The teacher-centered learning model is generally considered as a model of "instruction that is formal, controlled, and autocratic in which the instructor directs how, what, and when student learn" (Dupin-Bryant, 2004, p. 42). Teacher-centered learning comes in a variety of forms, such as direct instruction, which operates under several assumptions: students need direction and close supervision in order to maximize their learning; the amount of instructional and engaged time should be maximized; classrooms should be structured in such a way that the teacher is in control; and appropriate questioning techniques should be employed (Cunningham, 2008).

As mentioned above, the concept of student-centered learning has become overextended. Some approaches with characteristics of teacher-centered learning are often labeled as student-centered. For instance, Socratic inquiry is considered by some scholars a student-centered approach, because it involves question-based engagement of students. "The Socratic method of teaching is a student-centered approach that challenges learners to develop their critical thinking skills and engage in analytic discussion" (Coffey, n.d., para.1). While others insist that Socratic inquiry is teacher-centered in that the teacher selects and delivers the questions (Halstead, 2011).

\subsection{Definition Reconsidered}

Identity is a complex concept that can be understood differently in different disciplines. In some situations, it is difficult to find an agreed-upon definition of an absolute "student-centered" or "teacher-centered" learning approach. While these two approaches can be integrated in some cases, things may get confusing for those who are used to putting ideas into crisp and non-overlapping categories.

In fact, in most of the effective classrooms these two approaches are blended and used alternately. In the context of pedagogy, being at the "center" is generally defined in terms of the source of authority and controlling in the process of education. However, we will argue that this does not mean teacher hegemony or holding more power. "Student-centered" might look similar to the medical treatment term "patient-centered," which does not mean patients should decide on a treatment plan for themselves even though the plan would be very highly individually based. In this article, we do not intend to draw an exact dividing line between student-centered and 
teacher-centered model, neither do we favor which one of the two. We argue that it is a false choice to make between student-centered and teacher-centered approach. Education should be an endeavor embracing the oneness of teaching and learning. We prefer to describe education as an integrated whole which transcends the polarization of student-centered or teacher-centered teaching and learning.

\section{The Debate of Student-Centered versus Teacher-Centered Learning}

Teaching strategy is a complicated issue. There are plenty of discussions about the distinction between teacher-centered and student-centered pedagogy. Each pedagogy has its own unique qualities and shortcomings, strengths and challenges. As a result, the debate on student-centered versus teacher-centered education has prevailed for many decades. In recent decades, a great deal has been written on the shortages of teacher-centered education. For example:

- Teacher-centered pedagogy does not encourage students to interact with each other as they learn. When students work alone, they do not learn to collaborate with other students, and communication skills may suffer (Concordia University - Portland, 2013).

- Teacher-centered instruction can get boring for students. Students "are bored because there is little flexibility to spend more time and energy on those subjects that interest them most. Everybody is expected to learn the same material, at the same pace" (Education \& Evolving, 2008, p. 3).

- Students' minds may wander, or they may be out of mind, or miss important facts. "Anyone who has to sit through a long routine -- including a teacher's presentation -- is bound to drift off at some point" (Frondeville, 2009, para.3).

- Teacher-centered instruction doesn't allow students to express themselves, ask questions and direct their own learning. "Teacher-centered teaching mode...suppress the students' passion and initiative" (Gao, 2013, p. 1463).

However, the practice of student-centered education is not without problems. Opponents argue that there are many weaknesses of student-centered education:

- Students will become confused at the beginning level. Gaining self-study ability from a tutor is very necessary for an inexperienced learner, even though exploring and inquiring for knowledge is a leaner's own business. Sometimes an inspiring instructor is like a map or a guide. Without the navigation of experienced instructors, inexperienced learners might get lost in the world of large amounts of information, and it is hard for them to navigate an integrated education pathway which is fundamental for complex theory study, especially in science and engineering education. "Student-centered approaches rarely consider the actual knowledge being taught and learnt. There is little consideration of how the disciplinary knowledge is constructed and what norms and values underpin such constructions" (Mckenna, 2013, p. 1).

- Impeding students' academic achievement. Some research analysis concluded that "the traditional, teacher-centered approach generally produced higher academic achievement than the progressive, student-centered approach" (Chall, 2000, p. 171). "As the curriculum is designed by the teacher, it becomes easy to achieve the desired goals" (Umar, 2013). "In contrast to direct instruction, learner-centered techniques do not have a record of increasing academic achievement; they may, in fact, impede its development...Unfortunately, the progressive/constructivist approach is markedly inferior to traditional, 'teacher-centered' pedagogy, particularly when it comes to teaching students important skills like reading and math" (Cunningham, 2008, p. 3)

- Inefficiency in teaching and learning. Teaching efficiency has been submerged by an overemphasis on student-centered pedagogy. Placing too much emphasis on student-centered pedagogy may induce problems with distraction, purposelessness and lacking of self-control. The "attractive and colorful" student-centered classrooms did not live up to expectations. "...the result too often is a rising tide of noise and disorder. The upshot is the most fearful waste of precious time in the school day" (Spencer, 2001, para. 13-14). In the case of China, some Chinese teachers argue that adopting student-centered pedagogy is very challenging in China, as China has the largest population (over 1.3 billion) in the world, and class size, especially in some classrooms of general courses, is very big. Such a large number makes it hard to apply the student-centered pedagogy, such as pair work, group work, or role-play (Luo, 2010).

- Leading to school anxiety. It is an undisputable fact that students are different in characteristics, and there are always some introverted students who are smart but quiet, withdrawn or timid. They prefer to 
be learning quietly or on their own pace. However, in a student-centered class, these students might feel uncomfortable, anxious and stressed out when group work and presentation pedagogies are daily used. Some shy students find this pedagogy confusing, overwhelming or just plain annoying. Some even suffer from school phobia due to the above reasons.

A number of scholars review the student-centered model through the lens of cultural capital, social class and critical race theory. They argue that the student-centered model is not suited to the elementary education of working-class and lower-class families, especially those below the poverty level. In Spencer's (2001) words, "In countries that teach substantive, sequenced curricula, the vocabulary/knowledge gap narrows by the end of schooling. But in the United States, it actually grows...Knowing their children's deprivations, many black teachers and parents see the message of white progressive teachers that teaching facts and skills inhibits understanding and creativity as 'just another racist ploy to keep African-Americans down' " (para. 26; 29). Spencer (2001) worried about this situation is a hidden failure, which is all too widely replicated nationwide. "Deeply indoctrinated administrators, teachers, and their like-minded academic allies are so committed to progressivism that they will not even explore, outside that box, how schools could do better for deprived children. What an irony that 'progressives,' once seen as liberating, democratizing influences in education, have become the 'establishment,' stubbornly dogmatic and self-protective, at the expense of our neediest children" (para. 30).

The above situation is not an isolated phenomenon. Mckenna (2013) in South Africa argues in his article, "The Dangers of Student-Centered Learning - A Caution about Blind Spots in the Scholarship of Teaching and Learning," that student-centered approaches are often undertaken within the dominant autonomous discourse where student success or failure is seen to result from characteristics inherent in the student. The student is understood as an individual rather than as a member of a larger social group and there is equally little acknowledgement of the socially constructed nature of universities and the practices within them. The autonomous learner discourse, if taken to its logical conclusion in relation to the high failure and dropout rates in the universities in South Africa, can be revealed to be both elitist and racist (Mckenna, 2013).

\section{Relationship between Teaching and Learning through a Tai Chi Perspective}

In the debate of student-centered versus teacher-centered learning, there is an assumption that these two educational approaches are strictly oppositional to each other. It is a dichotomy of either black or white. In fact, in most educational scenarios, teachers and students have shared responsibilities and made endeavors together. Hence, it is best for teachers to use a dynamic combination of the two approaches and adapt their strategies to make sure each student achieve learning and make progress. A dynamic balance between student-centered and teacher-centered approaches is desirable. Based on this assumption, what does "a dynamic balance" mean? Is there any model to realize it? We hereby suggest that the ancient Chinese Tai Chi philosophy may shed light on an integrative approach.

Tai Chi thinking can be traced back to the period of ancient China 6000 years ago (Ming, 2009) and its original expression began to take shape 2500-3000 years ago in the text of I Ching (also known as the Classic of Changes or Book of Changes in English) and Tao Te Ching. The word of Tai Chi was firstly introduced in the Daoist classic Zhuangzi (Circa 3rd century B.C.E). Tai Chi also appears in the Xici, commentary to the I Ching, about the 3rd century B.C.E.. The Chinese character for Tai means "supreme; great; extreme; very", and Chi means "pole; extreme; the utmost point." Common English translations of this Chinese word are phonetic transcriptions "Tai Chi" or "Taiji"; or some literal paraphrases such as "Supreme Ultimate" (Zhang \& Ryden, 2002), "Great Ultimate" (Robinet, 2008), etc..

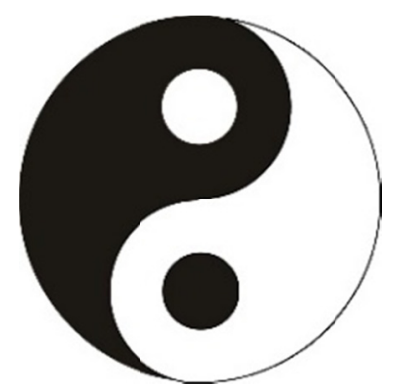

Figure 1. The Tai Chi Diagram 
Tai Chi was represented by the circle divided into yin (the black half) and yang (the white half), as shown in Figure 1, which describes how two apparently opposite or contrary forces are actually complementary, interconnected, and interdependent in the natural world, and how they give rise to each other as they interrelate to one another. "All things carry the yin at its back and the yang in front" (Tao Te Ching, Chapter 42). The Tao tells us that the world is composed of two complementary opposites: yin and yang. In nature, yin and yang combine in patterns of light and dark, male and female, acidity and alkalinity (PH), and so on. If yin and yang are "without unity, all things can not be produced and will become extinct" (Tao Te Ching, Chapter 39). Yin and yang can be thought of as complementary (rather than opposing) forces that interact to form a dynamic system of balance in which the whole is greater than the assembled parts.

Tai Chi is a unity of oppositeness and complementation. According to Tai Chi philosophy, student may be considered as "yin", while teacher as "yang." A Tai Chi model of education focuses on the dynamic interaction of the teacher and the student, and it transcends the dichotomy of student-centered and teacher-centered teaching. Varying and adapting are the core spirit of Tai Chi philosophy. The subjective position between teachers and students is not immutable. They may shift reciprocally in accordance with different individuals. "The reciprocal transformation of contraries is the movement of Tao" (反者道之动) (Tao Te Ching, Chapter 40). The dynamic and mutual transformation of teacher-centered and student-centered teaching characterizes a Tai Chi inspired educational philosophy.

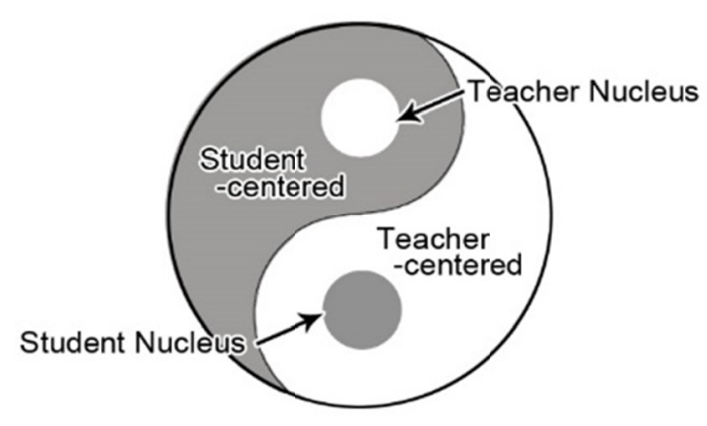

Figure 2. Double nucleuses of the Tai Chi model

The Tai Chi model as a dynamic model has "double nucleuses" that evolve into its contrary half. It appears in figure 1 that there is a black dot in the white half and a white dot in the black half. The "double nucleuses" of the Tai Chi model indicate that in yin there is an element of yang, and in yang there is an element of yin, and they can be transformed into each other and they are perpetually in interactive motions. We posit the "double nucleuses" phenomenon stands for the collaborative harmony in teacher-student relationships in that "you are in my mind and I am in your mind," and education may be viewed as a shared process growing out of interactions among teachers and students.

There is a white nucleus in the black half (Figure 2). As it is mentioned above, the white dot (i.e. yang) symbolizes the teacher while the black dot symbolizes the student (i.e. yin). The black half with a white nucleus indicates student-centered approach involving a teacher's effort, and it should not exist as a separate approach in the absence of teachers who play an active role in organizing, directing and counseling. Instead, it sets higher requirement for teaching skills. If a teacher can not guide a student-centered classroom, the teaching efforts would be worse than a traditional teacher-centered classroom, which has clear teaching plan and goals, and the teacher directs all classroom activities, so that they do not have to worry that students will miss an important topic for learning.

By contrast, there is a black nucleus enclosed within the white area (Figure 2). It indicates that the teacher-centered half doesn't mean neglecting students' existence. The black nucleus symbolizes teaching with a focus on the diversity of student's race, interest, personal characteristics, background knowledge, or any number of other factors, including what Gardner's theory of multiple intelligences describes (Gardner, 1999). Great teachers are always inspiring teachers. Regarding this condensed student nucleus, great teachers are always looking for possible approaches that are most beneficial for all of their students, by using differentiated strategies adapting to the unique needs, interests, and abilities of each student. 
The Tai Chi model of "double nucleuses" separately appearing in the contrary half may explain why there is an overlap between student-centered approach and teacher-centered approach in real educational contexts. "Some may use the term teacher-centered while having a practice that embraces many elements of a learner-centered approach. Just as common is the teacher who is proud of being learner-centered, but also has strong convictions about having some of the control or the curricular focus common in a teacher-centered philosophy. In the end, it isn't especially important to know where we fit" (Bull, 2014, para. 13). That is to say, we do not need to be entangled in the endless debates on who should be in the center and who should be in the periphery. Harmony and dynamic balance may be the ideal state of teaching-learning relationships.

In brief, Tai Chi partnership between teachers and students contributes to the building of a collaborative educational culture. In most cases in the classroom, it is best to have a combination of teacher-centered and student-centered approaches. When both approaches are synthetically used, it will in turn help students learn better and both teachers and students become active participants in the teaching-learning exchange. Students will benefit from the positive effects of both types of education while problems such as the negative effect of student passivity in teacher-centered education, or the loss of direction in a completely student-centered classroom, are effectively addressed, and an integrative, balanced educational culture is achieved.

\section{Four Dimensions of the Pedagogic Tai Chi Model}

Students are very different from one to another. Educators should try to cater to individual differences by making use of these differences. Many researchers support this opinion. For example, Howard Gardner's Theory of Multiple Intelligences expands the concept of intelligence to seven categories beyond the traditional recognized verbal and computational intelligences (Gardner, 1999). Marton and Booth's Theory of Variation argues that there is no single way to understand, experience or think about a particular phenomenon; indeed there is considerable variation in people's discernment. In learning, individual students make sense of new concepts in different ways, according to their existing understandings and frameworks of knowledge (Tong, 2012).

Education is an interactive process, hence there are no fixed patterns. Teacher-centered and student-centered learning may shift oppositely according to a variety of situations. We try to explore these situations and the rules of shifting. Specific to actual practice of teaching and learning, a Tai Chi model may be interpreted to comprise four pairs of dimensions: Teaching and Non-Teaching; Knowledge and Skills; Learning and Exploring; Permissiveness and High Expectation.

In the sections below, we try to explore these situations and the rules of shifting, maintaining a dynamic connection between education and personal experience.

\subsection{Teaching and Non-Teaching}

Teaching is for non-teaching. One of the most important goals of teaching is to help students to acquire self-learning skills, which we call the "non-teaching" aspect of education, e.g., the expectation that students will become self-directed learners as they mature and gain content knowledge. Let's take infant feeding as an example. At the beginning, a newborn baby does not have the ability to judge what kind of liquid she should choose to drink: natural breast milk or synthetic milk? It is hard for a neonate to choose. Teaching sometimes is like infant feeding. For those novices, if the teaching activities begin with student-centered pedagogy, it may put them into an uncertain, bewildered and lost state. An experienced teacher may give specific suggestions on learning to different types of pupils at the beginning. When a learner has acquired self-learning abilities step-by-step, the student-centered pedagogy becomes more necessary and relevant, and it is then the teacher-centered approach may transit into adopting a student-centered approach.

As in a Chinese saying, "Getting start requires the guide of a skilled master, one is excelling or not depends on the apprentice herself” (师傅领进门,修行在个人). The aim of teaching is to help students develop their self-learning capability to a level of acquiring knowledge and skills by themselves. "The teacher's job is to help students progress toward greater levels of independence as a learner. As learners are ready, the teachers relinquish greater control to the leaners. Learners eventually come to own more of the learning process, even to the point of being able to select what is to be learned (when appropriate), how to learn it, how to self-monitor for progress, along with how to assess and prove what is learned. Learners are given growing levels of control over the time, pace, and path of the learning" (Bull, 2014, para.12). The transition from teaching to non-teaching is accompanied by shifting from a teacher-centered approach to a student-centered approach, which is a typical dynamic interaction of Tai Chi movement. 


\subsection{Knowledge and Skills}

Acquiring knowledge and mastering skills are two important goals of education. Knowledge is a familiarity, awareness or understanding of someone or something, while skill is the learned ability to carry out a task. Generally speaking, in the procession of understanding abstract or unintelligible knowledge, a teacher's explanation or demonstration might be more efficient than students' learning on their own. As for skill training, teacher's demonstration can not replace students' drilling. Mastering a skill requires a more student-centered approach. For instance, if the case is to teach musical knowledge, such as musical notes, rhythm and so on, a teacher-centered explanation and performance will be more vivid and impressive than letting students to read musical textbook by themselves. But if the case is to learn how to play piano, students must drill to play the piano themselves, and the more effective approach must be a student-centered one.

The complexity of this problem is that, even in the case of knowledge teaching or skills training, the subject position of teacher or student is not absolutely immutable. When students have gained self-learning skills progressively, and become clearer as to what kind of knowledge they need to pursuit, they may check out information on their interests in library or via internet by themselves. In this process, teacher-centered pedagogy has been changing into student-centered pedagogy. Also, it is a typical Tai Chi interaction: two elements give rise to each other as they interrelate to one another.

\subsection{Learning and Exploring}

Satisfying curiosity and exploring the unknown world are human instincts. Learning and exploring are two important essential survival abilities of human beings. They are both equally important. Education is a combination of learning and exploration. Exploring ability may be developed upon the transfer of acquired knowledge. Just like a mansion, learning is the basement, and exploring is on a higher level. As an English saying goes: "No man is his craft's master the first day," hence students' moving from lower levels to higher levels needs scaffolds which are usually set up with the assistance of teachers. In the beginning, the teacher has a more authoritative and initiative role than the student, leading the learning process and adjusting the stride length and giving directions according to the individual level and needs of a student, till she has acquired self-learning abilities, then in this stage, the student would take more initiatives, and the teacher may transform to be a coach at the side who need not control the leaning content but instead guide the student's process of exploring.

As a Chinese saying goes, teachers may be those who "help somebody to get on a horse and escort her for a certain distance." As time goes on, at the guide and facilitation of a veteran, the novice would be more skilled and eventually reach a proficiency level of engaging in free exploration by herself. This changing process is accompanied by a teacher-centered approach shifting to a student-centered one. This evolutional change resembles the Tai Chi dynamic transformation movement. If we apply Tai Chi philosophy to the education sphere, it would become easier to understand and get the essence of the comprehensive application of seemingly opposite pedagogies.

\subsection{Permissiveness and High Expectation}

Teacher-centered approach does not mean hegemony by teachers disregarding student initiatives, while student-centered approach does not mean spoiling students at the cost of compromise on strict requirements. "Effective teachers care about their kids, while also pressing them to do well...As teachers can show high or low amounts of care, as well as high or low amounts of press, teachers can relate to students in four distinctly different ways" (Australian Society for Evidence Based Teaching. n.d. Relational Styles. para. 3-4). The diagram (Figure 3) about four styles of teacher-student relationships shows that when teachers adopt a high-performance style of relating to students, the students have better attitudes about school, and they achieve better results (Australian Society for Evidence Based Teaching. n.d.). 


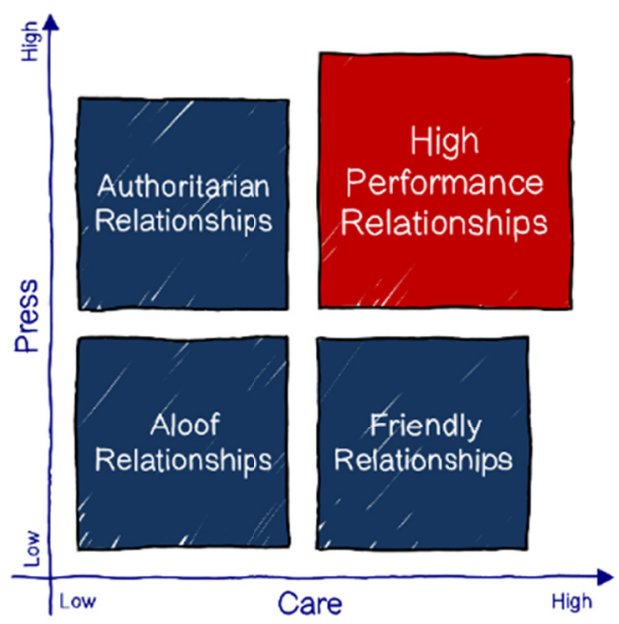

Figure 3. Four styles of teacher-student relationships

(Australian Society for Evidence Based Teaching. n.d.)

On this perspective dimensions to view pedagogic Tai Chi model, permissive attitude and high expectation may seem as polar opposites, but in fact they are sharing a dynamic balance in a Tai Chi model of productive teacher-students relationships: Teachers who forge high-performance relationships care for their students while simultaneously they allow room for their students to explore and express themselves. This self-consciousness and awareness of the dynamic balance of permissiveness and strictness will make teachers modify or improve on their practice.

\section{Tai Chi Philosophy Provides a New Perspective on Western Educational Theories}

Tai Chi thinking is the origin for both philosophical and religious Taoism, and has strongly influenced other schools, such as Legalism, Confucianism, Chinese Buddhism, and Chinese Kungfu and Tai Chi martial art. Tai Chi philosophy has stood the test of time. Due to its long history and popularity, it has been condensed, expanded, and reinterpreted in a variety of ways in Chinese culture.

Also, by using the Tai Chi philosophy, some classical western education theories may be brought to a new light. Let's take the theory of Bloom's Taxonomy as an example. Bloom's Taxonomy was created by Benjamin Bloom and several colleagues in 1948. It is a multi-tiered model of classifying education into six levels of complexity (Coffey, n.d.). Till now Bloom's Taxonomy has been widely used in education for classifying the levels of intellectual behavior important in learning (i.e. Bloom's Taxonomy) (Bloom, 1956). Hoping to add relevance for students and teachers in the $21^{\text {st }}$ century, a former student of Bloom's, Lorin Anderson (2001), and his colleagues, developed the taxonomy into a new version in 2001. In the revised taxonomy (Figure 4), there are six levels in the taxonomy, moving through the lowest thinking order processes to the highest thinking order. The lowest three levels are: Remembering, Understanding, and Applying. The highest three levels are: Analyzing, Evaluating, and Creating. 

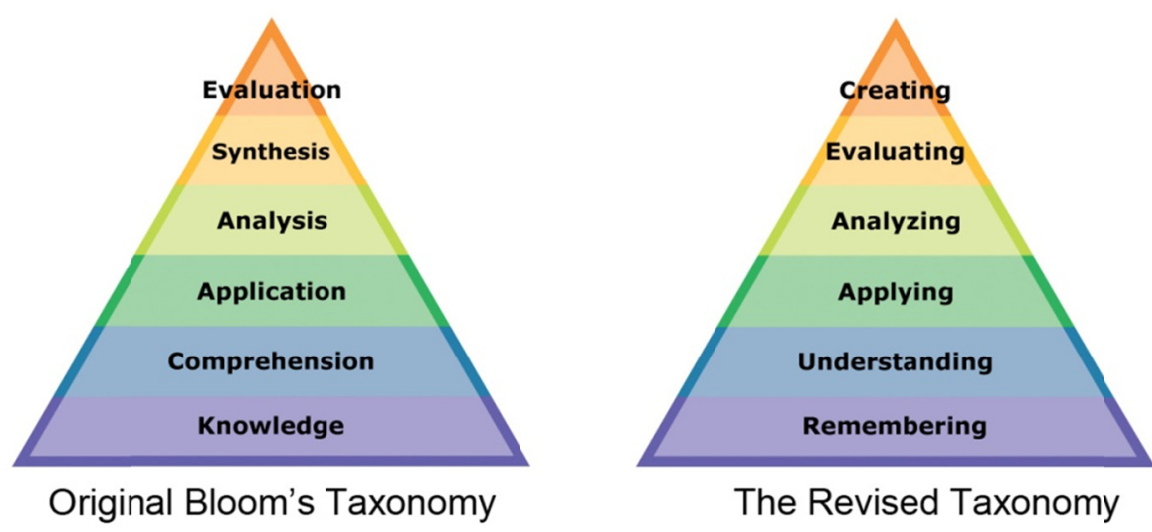

Figure 4. Original Bloom's Taxonomy and its revised version (Coffey, n.d.)

Compared with the original version, the features of student-centered learning is emphasized in the revised version. For instance, the bottom level of the original version is a neutral word "knowledge", while it changed to be "remembering" in the revised version, and the logical subject of remembering is student. The revised version is obviously a typical student-centered model. The new version's terms are defined as:

- Remembering: Retrieving, recognizing, and recalling relevant knowledge from long-term memory.

- Understanding: Constructing meaning from oral, written, and graphic messages through interpreting, exemplifying, classifying, summarizing, inferring, comparing, and explaining.

- Applying: Carrying out or using a procedure through executing, or implementing.

- Analyzing: Breaking material into constituent parts, determining how the parts relate to one another and to an overall structure or purpose through differentiating, organizing, and attributing.

- Evaluating: Making judgments based on criteria and standards through checking and critiquing.

- Creating: Putting elements together to form a coherent or functional whole; reorganizing elements into a new pattern or structure through generating, planning, or producing (Anderson \& Krathwohl, 2001, pp. 67-68).

The revised Bloom's Taxonomy is a model described from the perspective of student-centered learning. However, as we have posited, education is an interaction between students and teachers, hence the revised Bloom's Taxonomy only reflects the student's unilateral action. As shadow cannot exist without light, learning is more or less the symbiotic partnership of teaching and learning. When the philosophy of Tai Chi is incorporated into Bloom's Taxonomy, the other commensal part of a teacher-centered approach would be factored in, which brings forth an integrated education model consisting of both students and teachers as dynamic players.

Viewed from a Tai Chi perspective, the revised Bloom's Taxonomy may be deduced into a Tai Chi model. Corresponding to the six student-centered levels of the revised Bloom's Taxonomy, we develop the other hidden part of six teacher-centered levels, with teachers' roles going from being directive to be increasingly facilitative as students acquire their autonomy in learning (see Figure 5). We draw this new model in the shape of a Tai Chi diagram to illustrate an integrative education system involving the joint efforts of both teachers and students. Coinciding with the revised Bloom's Taxonomy, the other commensal levels from lowest to the highest are: instructing, explaining, directing, coaching, consulting, and facilitating. 


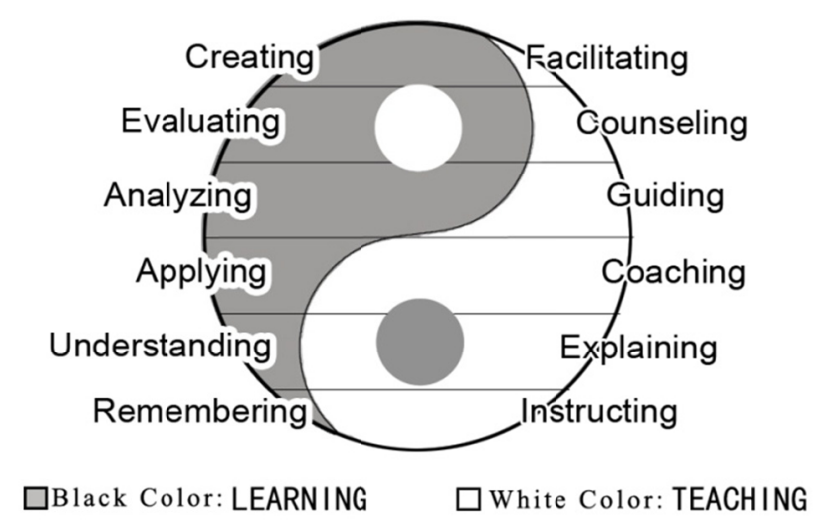

Figure 5. New version of the revised Bloom's Taxonomy in Tai Chi perspective

- Instructing: interpreting abstract concepts, showing the knowledge map, providing instruction on how to grasp the basic essentials of a complex knowledge system.

- Explaining: making (an idea, situation, or problem) clear and easier to be understood by describing it in more details or revealing relevant facts or ideas.

- Coaching: setting an example, demonstrating and showing the way to apply knowledge; giving commands or instruction in the training and operation to improve a skill.

- Guiding: playing the role as a tutor, helping students to summarize, guiding or directing students to analyze independently and to draw a conclusion.

- Counseling: giving counsel or advice, helping students to evaluate, rethink, and make judgments. The teacher is always there to assist, but refrain to give answers.

- Facilitating: the teacher attending as an instigator, a friend, accompanying students with encouragement, guidance, holding open discussions, or sometimes playing as a collaborative partner.

From the lower level to the higher level, the teacher's role changes from strong to weak. In the Figure 4, the area of black (yin, i.e. learning) or white (yang, i.e. teaching) in different level represents the subjective roles of the student or the teacher. The larger the area is, the more positive role the teacher or the student plays, and vice versa. For example, in the top level of "creating and facilitating," the black area is larger than that of the white. It indicates that in the stage of creating and innovation, students play more initiating and positive roles than teachers. While in the base level of "remembering and constructing," the white area is larger than the black one, which indicates teachers should play a more authoritative role to provide knowledge, helping students to be aware of the fundamentals of a knowledge system, in case that some students do not know what they should know at the first beginning. While it seems that the area of black and white are opposite from each other, the Tai Chi approach indicates education is a shared interaction between teachers and students in which both are responsible for pushing forward. In short, the revised Bloom's Taxonomy reconstructed with Tai Chi philosophy may help bring about the dynamic wholeness of education which is a coordination of the endeavors of both students and teachers.

\section{Conclusion}

Education is a process of interaction between teachers and students, which deserves more attention than engaging in incessant argument about which group should dominate the center. According to the Tai Chi philosophy, teaching and learning may look like two contrary forces but in actuality they are complementary, interconnected, and interdependent in education. Teaching and learning give rise to each other as they interrelate to one another. The dynamic exchange of teacher-centered and student-centered pedagogy forms an organic complementary system in which the whole is greater than the assembled parts.

Respecting the difference of individual students, the Tai Chi philosophy acknowledges that every individual possesses a unique blend of multiple intelligences. The teaching style may transform in accordance with the different aptitude of individual students as well as the different developmental stages of the students. In other words, education is a highly individualized process. Even in the same class with the same teacher, the pedagogies should dynamically vary according to the individual differences of the students. 
The subjective position between teachers and students may transform reciprocally. Just as every student is different, every education strategy to fit students' needs is also ever-changing. Students will be better served by a broader vision of education, wherein teachers use a variety of methodologies, exercises and activities to reach all students, not only those who excel at linguistic and logical intelligence. Providing effective education challenges educators to find "ways that will work for this student learning this topic" (Gardner, 1999, p.154). Introducing Tai Chi thinking into education may help educators to deal with educational challenges with highly personalized approaches. Tai Chi thinking helps educators to understand the relationship between teaching and learning with a dialectical view. Further, Tai Chi thinking advocates adapting and coordinating, which helps to match teaching method and students' individual needs and levels. Last but not least, beyond the dichotomy of teacher-centered and student-centered model, Tai Chi thinking resists a unipolar approach while promoting harmonious symbiosis, a dynamic balance of various pedagogies, and dynamic adaption of teaching and learning, which is expected to help students learn effectively and achieve educational successes.

\section{References}

Anderson, L. W., \& Krathwohl, D. R. (Eds.). (2001). A taxonomy for learning, teaching and assessing: A revision of Bloom's Taxonomy of educational objectives. New York: Longman.

Australian Society for Evidence Based Teaching. (n.d.) What Everyone Needs to Know About High-Performance, Teacher Student Relationships. Retrieved from http://www.evidencebasedteaching.org.au/crash-course-evidence-based-teaching/teacher-student-relationshi ps/

Bloom, B.S. (Ed.). Engelhart, M.D., Furst, E.J., Hill, W.H., \& Krathwohl, D.R. (1956). Taxonomy of Educational Objectives, Handbook I: The Cognitive Domain. New York: Longman.

Bull, B. (2014). Are You Teacher-Centered, Learner-Centered, or Both? Retrieved from http://etale.org/main/2014/12/03/3-types-of-teacher-centered-5-types-of-learner-centered-which-ones-are-y ou/

Chall, J. (2000). The Academic Achievement Challenge: What Really Works in the Classroom? New York: Guilford Press.

Coffey, H. (n.d.). Bloom's Taxonomy. Retrieved from http://www.learnnc.org/lp/pages/4719\#noteref1

Coffey, H. (n.d.). Socratic method. Retrieved from http://www.learnnc.org/lp/pages/4994

Concordia University - Portland. (2013). Which is Best: Teacher-Centered or Student-Centered Education? Retrieved from http://education.cu-portland.edu/blog/classroom-resources/which-is-best-teacher-centered-or-student-center ed-education/

Cunningham, G.K. (2008). UNC Education Schools: Helping or Hindering Potential Teachers? Retrieved from http://www.popecenter.org/inquiry_papers/article.html?id=1949

Dupin-Bryant, P. A. (2004). Teaching Styles of Interactive Television Instructors: A Descriptive Study. The American Journal of Distance Education, 18(1), 39-50. http://dx.doi.org/10.1207/s15389286ajde1801_4

Education \& Evolving. (2008). Rethinking the Student-Centered Classroom. Retrieved from http://www.educationevolving.org/pdf/TypeIIRethinkingTheClassroom.pdf

Frondeville, T. (2009). How to Keep Kids Engaged in Class. Retrieved from http://www.edutopia.org/classroom-student-participation-tips

Gao, L. (2013). Study on Reform of Public Physical Education Management in Chinese Universities. In Qi, E.; Shen, J., \& Dou, R. (Eds.), The 19th International Conference on Industrial Engineering and Engineering Management (pp.1461-1468). Heidelberg: Springer. http://dx.doi.org/10.1007/978-3-642-38433-2

Gardner, H. (1999). Intelligence Reframed: Multiple Intelligences for the 21st Century. New York: Basic Books.

Halstead, J. (2011). Navigating the new pedagogy: Six principles that transform teaching. Lanham, MD: Rowman \& Littlefield Education.

King, A. (1993). From Sage on the Stage to Guide on the Side. College Teaching, 41(1), 30-35 http://dx.doi.org/10.1080/87567555.1993.9926781

Luo, L. (2010). Reflection on Teacher-centered strategy in college English Classroom. Read and Write Periodical, 7(2), 14-15. http://dx.doi.org/10.16071/j.cnki.cn51-1650/g4.2010.02.023 
Masouleh, N.S., \& Jooneghani, R.B. (2012). Learner-Centered Instruction: A Critical Perspective. Journal of Education and Practice, 3(6), 50-59. Retrieved from http://iiste.org/Journals/index.php/JEP/article/view/1637/1608

Mckenna, S. (2013). The Dangers of Student-Centered Learning - A Caution about Blind Spots in the Scholarship of Teaching and Learning. International Journal for the Scholarship of Teaching and Learning, 7(2), Article 6. Retrieved from http://digitalcommons.georgiasouthern.edu/ij-sotl/vol7/iss2/6

Ming, C. (2009). Exploration of Tai Chi Diagram. Sichuan: Sichuan University Press. (in Chinese)

Robinet, I. (2008). Wuji and Taiji, Ultimateless and Great Ultimate. In Pregadio, F. (Ed.), The Encyclopedia of Taoism. London: Routledge

Sadker, D.M., \& Zittleman, K. (2006). Teachers, schools and society: A brief introduction to education. New York: McGraw-Hill Higher Education.

Spencer, L.C. (2001). Progressivism's Hidden Failure. Education Week, 20(24), 29, 32-33. Retrieved from http://www.edweek.org/ew/articles/2001/02/28/24spencer.h20.html

Tong, S. A. (2012). Applying the Theory of Variation in Teaching Reading. Australian Journal of Teacher Education, 37(10). http://dx.doi.org/10.14221/ajte.2012v37n10.3

Umar, F. (2013). Advantages and Disadvantages of Teacher centered Curriculum Approach. Retrieved from http://www.studylecturenotes.com/curriculum-instructions/advantages-and-disadvantages-of-teacher-center ed-curriculum-approach

Zhang, D., \& Ryden, E. (2002). Key Concepts in Chinese Philosophy. New Haven: Yale University Press.

\section{Copyrights}

Copyright for this article is retained by the author(s), with first publication rights granted to the journal.

This is an open-access article distributed under the terms and conditions of the Creative Commons Attribution license (http://creativecommons.org/licenses/by/4.0/). 